\title{
A novel approach to maintain positive pressure ventilation during difficult Montgomery T-tube placement
}

\author{
Fnu Kailash, MD · Sean L. DaSilva, MD • \\ Frank E. Block Jr., MD
}

Received: 15 March 2009/Accepted: 11 June 2009/Published online: 7 July 2009

(c) Canadian Anesthesiologists' Society 2009

\section{To the Editor,}

The Montgomery tracheal tube (T-tube) is a surgical device used to maintain a compromised airway following complex tracheal injury. ${ }^{1}$ We report an effective and novel use for the endobronchial multiport airway ventilating adapter $\left(\mathrm{Cook}^{\circledR}\right.$, Bloomington, IN, USA) to maintain positive pressure ventilation during difficult Montgomery T-tube placement.

A 50 -yr-old man with a body mass index of $38 \mathrm{~kg} \cdot \mathrm{m}^{-2}$ and clinically significant bilateral airspace disease was scheduled for micro-direct laryngoscopy, bronchoscopy, and Montgomery T-tube placement after he had sustained blunt laryngotracheal injuries (thyroid and cricoid cartilage fractures with posterior displacement of anterior cartilage and significant superglottic hematoma). The patient underwent a tracheostomy (size 8.0 cuffed Shilley) to secure his airway. During the Montgomery T-tube placement under general anesthesia, difficulty in ventilation arose while attempting to occlude the upper intralaryngeal section of the T-tube with a Fogarty vascular catheter (Edwards Lifesciences ${ }^{\circledR}$, Irvine, CA, USA) via the extratracheal lumen. This procedure is designed to prevent leaks of volatile anesthetic and fresh gas flows during positive pressure ventilation (as originally described by Montgomery). ${ }^{1}$

In discussion with the otorhinolaryngologists, a plan was devised to ventilate the patient's lungs following re-insertion of the T-tube. A standard endobronchial multiport airway adapter $\left(\mathrm{Cook}^{\circledR}\right)$ was attached to the extratracheal limb of the Montgomery T-tube via a standard $15 \mathrm{~mm}$ endotracheal tube connector (7.5 mm polyvinyl endotracheal tube). The Ttube was re-inserted, and a Fogarty vascular catheter was

F. Kailash, MD (ه) · S. L. DaSilva, MD · F. E. Block Jr., MD University of Arkansas for Medical Sciences, Little Rock, USA e-mail: kailashkailash@uams.edu passed through the $30^{\circ}$ angled port of the Cook ${ }^{\circledR}$ Multiport Airway Adapter. The catheter was then fed into the upper limb of the T-tube under direct laryngoscopy, and the balloon was inflated to create a tight seal. The right-angled port of the multiport adapter was used for positive pressure ventilation and standard end-tidal carbon dioxide monitoring (Fig. 1). The Montgomery T-tube was secured, and proper positioning of the upper intratracheal stem was confirmed by direct laryngoscopy. Ventilation of the patient's lungs was maintained through the multiport airway adapter during these critical maneuvers.

The Montgomery T-tube can present various challenges to anesthesiologists during its placement, including the potential for acute loss of the airway, inadequate administration of inhalation agents, and inadequacy of controlled mechanical ventilation. Various insertion techniques were developed to overcome some of these difficulties. This case was unique because the patient's complex laryngotracheal injuries and associated hypopharyngeal and supraglottic lesions precluded the use of the laryngeal mask airwayMontgomery T-tube technique as described by Guha et al. ${ }^{2,3}$ Described, in this case, is a "combined technique" of passing an endotracheal tube through the extratracheal lumen and the intratracheal portion of the T-tube distal to the tracheal lesion. ${ }^{4}$ While it can be argued that this "combined technique" may offer the benefit of a secured airway through which positive pressure ventilation can be performed, we would argue that our method is feasible and effective with little interruption to monitoring of ventilation. Placement of the endotracheal tube fed through the extratracheal lumen of the T-tube to the distal trachea may also be complicated by potential kinking and acute loss of the airway. Furthermore, it may not be apparent during this difficult placement whether the kink was due to the endotracheal tube or due to the T-tube. 


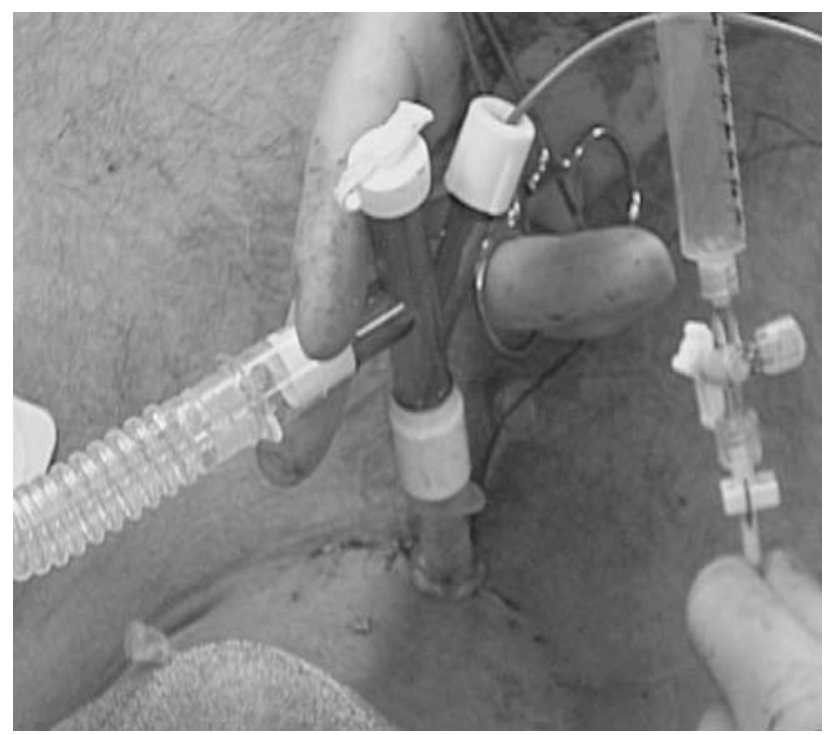

Fig. 1 Cook $^{\circledR}$ Multiport Adapter connected to the extratracheal lumen of the Montgomery T-tube in situ via a standard $15 \mathrm{~mm}$ endotracheal tube connector. Anesthesia breathing circuit (left) and Fogarty catheter (right) via additional ports of the multiport adapter
This technique may have several benefits over previously described techniques and may serve as a model for both anesthesiologists and otolaryngologists in the management of such complicated airway cases necessitating Montgomery T-tube placement.

Competing interests None declared.

\section{References}

1. Montgomery WW. Manual for care of the Montgomery silicone tracheal T-tube. Ann Otol Rhinol Laryngol Suppl 1980; 89(4 Pt 5): $1-8$.

2. Guha A, Mostafa SM, Kendall JB. The Montgomery T-tube: anaesthetic problems and solutions. Br J Anaesth 2001; 87: 78790.

3. Uchiyama $M$, Yashino A. Insertion of a Montgomery T-tube. Anaesthesia 1995; 50: 476-7.

4. Kim KT, Sun K, Shin JS, Kim HM. A simple and secure technique for tracheal T-tube insertion. Eur J Cardiothorac Surg 2001; 20: 1037-9. 